\title{
Saturated Non-esterified Fatty Acids Measurement
}

National Cancer Institute

\section{Source}

National Cancer Institute. Saturated Non-esterified Fatty Acids Measurement. NCI

Thesaurus. Code C80206.

The determination of the amount of saturated non-esterified fatty acids present in a sample. 